\title{
The Association between Direct and Relational Bullying and Behaviour Problems among Primary School Children
}

\author{
Dieter Wolke, Sarah Woods, Linda Bloomfield, and Lyn Karstadt \\ University of Hertfordshire, Hatfield, U.K.
}

\begin{abstract}
The prevalence of direct and relational bullying and their differential relationship to behaviour problems in young primary school children was investigated. Individual interviews were conducted with 1982 children aged 6-9 years (mean age 7.6 years) and 1639 parents completed the Strength and Difficulties Questionnaire regarding behaviour problems of their children. Of the 1639 children with both data sets, $4.3 \%$ were direct bullies, $39.8 \%$ victims, and $10.2 \%$ both bullied and were victimised frequently (bully/victims). The rates for relational bullying were $1.1 \%$ bullies, $37.9 \%$ victims, and $5.9 \%$ bully/victims. All children involved in direct bullying had significantly increased total behaviour problems, hyperactivity, conduct problems, and peer problem scores, and lower prosocial behaviour scores compared to those not involved in bullying (neutrals). Findings were similar for relational bullying involvement and behaviour problems for bully/victims and victims but less pronounced. Relational bullies had the lowest behaviour problem scores while being rated the least prosocially inclined children, consistent with the concept of a cool manipulator. Overall, direct bully/victims and children who were involved in both direct and relational bullying behaviour had the highest rates of behaviour problems. No relationship between victimisation and increased emotional problems were found. Those involved in bullying behaviour who show externalising and hyperactivity problems in primary school may be at increased risk for persistent conduct problems. Different interventions may be needed for those involved in relational bullying only, both direct and relational bullying, and those with additional behaviour problems.
\end{abstract}

Keywords: Aggression, behavioural problems, bullying, conduct disorder, hyperactivity, victimisation.

Abbreviations: SDQ: Strengths and Difficulties Questionnaire.

\section{Introduction}

As defined by Olweus (1991, 1999, p. 10) "a student is being bullied or victimised when he/she is exposed repeatedly and over time to negative action on the part of one or more other students" with the intention to hurt. It usually involves an imbalance in strength, either real or perceived (Craig, 1998; Whitney \& Smith, 1993). Bullying behaviour constitutes a spectrum of actions including physical (hitting, kicking, pinching, taking money or belongings, etc.) and verbal (name calling, cruel teasing, taunting, threatening, etc.) aggression (Boulton \& Underwood, 1992). Recently another domain of bullying behaviour has been described, namely relational bullying/aggression. Crick and Grotpeter (1995) define relational aggression as the hurtful manipulation of peer relationships/friendships that inflicts harm on others through behaviours such as "social exclusion" and "malicious rumour spreading". Surveys of school children illustrate the depth and diversity of the bullying problem, with rates of frequent physical and verbal victimisation ranging from $8 \%$ to $46 \%$ (Baldry, 1998; Bentley \& Li, 1995; Boulton \& Smith, 1994; Boulton \&

Requests for reprints to: Professor Dieter Wolke, University of Hertfordshire, Department of Psychology, DWRU, College Lane, Hatfield, AL10 9AB, U.K.

(E-mail: D.F.H.Wolke@herts.ac.uk).
Underwood, 1992; Byrne, 1994; Gasteiger-Klicpera \& Klicpera, 1997; Genta, Menesini, Fonzi, Costabile, \& Smith, 1996; Hanewinkel \& Knaack, 1997; Harachi et al., 1996; Hirano, 1992; Kumpulainen et al., 1998; Menesini et al., 1997; Mooij, 1992; Morita, Soeda, Soeda, \& Taki., 1999; Olweus, 1999; O'Moore \& Hillery, 1989; O'Moore, Kirkham, \& Smith, 1997; Perry, Kusel, \& Perry, 1988; Vettenburg, 1999; Whitney \& Smith, 1993; Wolke \& Stanford, 1999). In contrast, rates of relational bullying victimisation are mostly unknown.

Concern has been expressed that bullying experiences may lead to serious psychological and mental health problems for school children. Most investigations to date have focused on behaviour problems in victims of physical or overt bullying and reported on concurrent relationships to emotional problems. Sharp (1995) surveyed a large sample of secondary school children where $34 \%$ reported that being bullied was stressful and $11 \%$ viewed it as extremely stressful. Several studies have indicated that victimisation is concurrently associated with lowered self-esteem (Austin \& Joseph, 1996; Boulton \& Smith, 1994; Callaghan \& Joseph, 1995; Egan \& Perry, 1998; Matsui, Kakuyama, Tsuzuki, \& Onglatco, 1996; Mynard \& Joseph, 1997; Neary \& Joseph, 1994; Rigby \& Slee, 1993), depression (Austin \& Joseph, 1996; Callaghan \& Joseph, 1995; Craig, 1998; Neary \& Joseph, 1994; Salmon, James, \& Smith, 1998; Slee, 1995) and increased anxiety (Craig, 1998; Salmon et al., 1998; Slee, 
1994) or general mental health problems (Slee, 1995; Slee \& Rigby, 1993). Salmon et al. (1998) further suggested that victims had higher scores on a scale assessing a tendency to lie. A recent short-term longitudinal study by Kochenderfer and Ladd (1997) reported that victimisation appears to be a precursor of children's loneliness and school avoidance and that the magnitude of the victimisation problem is related to school adjustment problems. Rigby (1999) also reported that poor mental health in senior school girls was associated with victimisation experiences 3 years earlier. Schwartz, McFayden-Ketchum, Dodge, Petit, and Bates (1998), utilising teacher and parent reports rather than selfreports, found that victimisation, both concurrently and at a follow-up 2 years later, was related to externalising/undercontrolled behaviour problems and not to internalising problems.

The majority of studies to date have been conducted with children older than 7 years of age and secondary school students (e.g. Austin \& Joseph, 1996; Craig, 1998; Mynard \& Joseph, 1997; Rigby, 1999; Salmon et al., 1998; Slee, 1994). There is a lack of studies on young primary school children at the beginning of their school career before experiences of victimisation may have become ingrained. Research concerning the behavioural characteristics of victims in young school children would be advantageous in light of findings from retrospective studies with adults that victimisation usually starts in the primary school years. Adults who suffered from bullying in childhood have been found to be more often depressed, to have poorer self-esteem (KIDSCAPE, 1998; Olweus, 1993), and to have more difficulties with sexual relationships (Gilmartin, 1987) in adulthood. Rigby's (1998) recent review suggests that the association of relatively poor health, both physical and mental, with current or recent peer victimisation may be limited to younger adolescent students.

Controversy remains whether bullies are confident and "cool" planners of their tormenting of others (Sutton \& Smith, 1999), are anxious, depressed, or insecure individuals (Salmon et al., 1998), or are children with behaviour problems such as hyperactivity and conduct disorder (Farrington, 1993). Olweus (1981, 1984, 1986, cited in Smith et al., 1999, p. 17) and Pulkkinen and Tremblay (1992) found that bullies did not suffer increased anxiety levels, insecurity, or low levels of selfesteem; in fact, quite the opposite. Conversely, others have reported that bullies may be depressed and dislike school (Salmon et al., 1998; Slee, 1994, 1995) and suffer from elevated anxiety levels (Craig, 1998).

Previous reports have predominantly classified children as either bullies, victims, or not involved in bullying behaviour as either a bully or victim. However, it is now evident that this is a gross oversimplification of bullying behaviour, as a sizeable group of children can be categorised as bully/victims (children who both bully others and are victims of bullying) (Austin \& Joseph, 1996; Boulton \& Smith, 1994; Kumpulainen et al.,1998; Whitney \& Smith, 1993). Bully/victims, often considered as victims in previous victimisation research (e.g. Olweus, 1993; Salmon et al., 1998), are a sizeable group, as large or larger in relative frequency than the group of "pure" bullies (children who bully and do not become victims at other times; Austin \& Joseph, 1996; Wolke \& Stanford, 1999; Wolke, Woods, Schulz, \& Stanford, 2000). A recent review indicated that the characteristics, social cognitions, and behaviours of bullies, victims, and bully/ victims may differ considerably (Wolke \& Stanford, 1999). Few studies have considered the consequences of bullying in terms of behavioural and psychological problems for bully/victims. Those studies that have, have reported that bully/victims are a distinct group who may be at the highest risk for behaviour problems and related psychological symptoms. Austin and Joseph (1996) found that bully/victims scored more highly on behavioural conduct problems than bullies, victims, and neutral children and suffered elevated depression scores, whereas Mynard and Joseph (1997) found that bully/victims scored higher on neuroticism and psychoticism scales than children who were not involved in bullying behaviour. Kumpulainen et al. (1998) conducted the largest bullying study of 8-9-year-old children to date, involving nearly $10 \%$ of children of that age-group in Finland and utilising parent, teacher, and self-reports of behavioural and emotional problems. The major findings of this study were that those involved in any form of bullying (bullies, bully/victims, victims) had more behavioural problems than children not involved in bullying. The bully/victims had the highest rates of behaviour disturbance, in particular externalising and hyperactivity problems for both genders, and the girls also had more internalising problems according to parent reports. Both "pure" victims and "pure", bullies were significantly more often rated as hyperactive and as having more internalising problems than neutral children. Higher rates of psychological disturbance were reported by the parents and teachers for all groups involved in bullying compared to self-reports by the children themselves. In particular, "pure" bullies were least likely to report significant behavioural disturbance in contrast to parents or teacher reports. Furthermore, bully/victims were 6- to 10 -fold more likely to have been referred for psychiatric consultation than children not involved in bullying. Referral rates for victims and bullies were similar (2- to 5-fold according to gender) compared to neutral children. These findings indicate that all children involved in bullying are at higher risk for behaviour problems and that victims have a variety of behaviour problems including internalising, hyperactivity, and conduct problems when data sources other than the children's self-report are utilised. The highest risk group for behaviour problems, according to this Finnish sample, appears to be bully/ victims.

The relationship between relational bullying, psychological wellbeing, and behaviour problems is not well documented. Craig (1998) examined the association between relational/indirect bullying and children's reported anxiety and depression. Hierarchical regression indicated that anxiety scores were significantly predicted by indirect and verbal aggression and victimisation. Thus, those who had higher indirect aggression or victimisation scores appeared to be more anxious. Sharp (1995) reported that indirect bullying was associated with higher levels of stress compared to direct bullying. Crick and colleagues (Crick, 1996; Crick \& Bigbee, 1998) showed that relational aggression contributes to predictions of future school adjustment beyond that of overt aggression.

There are still a number of uncertainties regarding the concurrent association between bullying behaviour and behaviour problems. First, most previous investigations have relied on self-report techniques (e.g. SPPC, Harter, 1985; The Junior Eysenck Personality Questionnaire, JEPQ, Eysenck \& Eysenck, 1975; Birleson Depression Inventory, Birleson, 1981). This may have resulted in an 
inflated picture of symptoms reported by victims of bullying and under-reporting of behaviour problems by bullies who wish to maintain a "cool image" (Kumpulainen et al. 1998). Second, there is a lack of knowledge regarding the association of bullying behaviour and behaviour problems in young primary school children. This is partly due to the fact that the Olweus (1978) self-report bullying questionnaire is not suitable for young children and alternative techniques such as individual interviews with children are required (Baldry, 1998; Boulton, 1993; Boulton \& Smith, 1994; Smith \& Levan, 1995). Third, many studies reported differences in mean scores on behavioural scales. It is not clear, with few exceptions (Kumpalainen et al., 1998), whether those involved in bullying have clinically significantly raised behaviour problem scores. Fourth, those who bully and become victimised at other times (bully/victims) appear to be at highest risk for behavioural problems. This research requires replication in young primary school children. Fifth, there is no research to date that has documented whether direct versus relational bullying has differential effects on reports of behaviour problems and whether those involved in both forms of bullying behaviour may be at the highest risk for concurrent behaviour problems.

The aims of the present study were threefold: (1) to investigate the prevalence of direct and relational bullying among primary school children by means of individual interviews; (2) to establish the extent of behaviour problems for children involved in direct or relational bullying as either "pure" bullies, "pure" victims, bully/ victims, or neutral children using parental reports as opposed to self-reports; (3) to examine whether there are differential effects of direct and relational bullying on parent reports of behaviour problems and whether those involved in both forms of bullying show the most behaviour problems.

\section{Method}

\section{Population}

Parents of children in 78 classes in 31 primary schools in Hertfordshire and North London were approached. Of the 2201 children in the 78 classes, $107(5.4 \%)$ children did not participate as their parents declined permission and a further $112(5.7 \%)$ were not present on the days of interviewing. Of the participating children $(N=1982), 886$ were in Year 2 and 1096 in Year 4. The age range was 6 to 9 years of age with an average age of 7.6 years $(S D$ 1.0) (Year 2: 6.7 years, $S D$ 0.6; Year 4: 8.3 years, $S D 0.6$ ). Total participation rate for the interviews was $88.9 \%$ of all pupils.

\section{Procedure}

The study had received ethical permission from the University of Hertfordshire Ethical Committee and all instruments and information were lodged with Hertfordshire Education Council. The head teachers, teachers of the Year 2 and 4 classes, and school governors were approached in writing, providing them with full written documentation about the study. They were offered opportunities to consult with the research leader or research assistants via telephone or personal consultation in the school. When the head teacher and class teachers consented to participate in the study, written information about the study and a nonconsent form (parents were asked to sign if they did not want their child to take part) was passed to all parents via the pupils in sealed envelopes. On prearranged dates all pupils were interviewed individually in a private room in the school by
Table 1

Sample Data

\begin{tabular}{lrcc}
\hline & $\begin{array}{c}\text { Total group } \\
(N=1982)\end{array}$ & $\begin{array}{c}\text { Returned Qs } \\
(N=1639)\end{array}$ & $\begin{array}{c}\text { \% returned } \\
(82.69)\end{array}$ \\
\hline Year group & & & \\
$\quad$ Year 2 & $886(44.7 \%)$ & $722(44.1 \%)$ & 81.5 \\
Year 4 & $1096(55.3 \%)$ & $917(55.9 \%)$ & 83.7 \\
Gender & & & \\
$\quad$ Male & $1019(51.4 \%)$ & $814(49.7 \%)$ & 79.9 \\
Female & $963(48.6 \%)$ & $825(50.3 \%)$ & 85.7 \\
Ethnicity & & & \\
$\quad$ White & $1805(91.1 \%)$ & $1500(91.5 \%)$ & 83.1 \\
Other & $177(8.9 \%)$ & $139(8.5 \%)$ & 78.5 \\
\hline
\end{tabular}

one of four trained interviewers (postgraduate psychologists). After the interviews were completed (usually over several days in each school), participating children were given sealed envelopes to hand to their parents. To help the children to remember and to motivate them to hand the envelope to the parents, a polaroid photo made of each individual child by the researchers was stapled on to each of the envelopes. The letter included the behaviour questionnaire and an envelope allowing the parents to return it to the teacher sealed or, alternatively, they could send it to the research team directly.

\section{Instruments}

Bullying interview. Children were interviewed individually using a standard structured interview. The children were first asked some open questions about the family and school to make them feel at ease. This was followed by standard questions about friendships and social relationships in school (not reported here). The part of the interview that is subject to this report was adapted from the Olweus (1991) Bullying Questionnaire. First, children were asked whether they had experienced any of six behaviours (direct bullying) in the last 6 months that had upset them: (1) Having been called bad or nasty names. (2) Having belongings taken. (3) Having lies told about them. (4) Having nasty tricks played on them. (5) Having been threatened or blackmailed. (6) Having been hit or beaten up. If the child answered that he or she had experienced any of these behaviours, the child was asked to give examples and describe how this had happened. This was done to ascertain that the behaviours experienced were carried out with intent by the perpetrator(s) to upset the child rather than having occurred by accident or during play fighting, etc. Those children who had experienced one or more of these behaviours were asked how frequently these incidents happened in the last 6 months (seldom : 1-3 times during past 6 months; frequently: 4 times or more during past 6 months; very frequently: at least once per week). To aid children's reference to approximately 6-month periods, anchors such as "since last Christmas", "since the summer holidays", etc. were used. The children were further asked where these behaviours took place (playground, corridor, classroom, on way to/from school, other areas such as toilets, changing rooms), which class the perpetrator usually came from (own class, parallel class, higher class, lower class, other school), who the perpetrator(s) were (boys, girls, boys and girls together), whether they told the teacher, and whether they told their parents. The six behaviours were then repeated and the child asked whether they have used these behaviours to upset other children and how often they had done this over the last 6 months (never or seldom: 1-3 times during past 6 months; frequently: 4 times or more during past 6 months; very frequently: at least once per week).

Subsequently, children were asked four questions relating to relational bullying at school: (1) Other children saying that they didn't want to play with them. (2) Other children saying that they would not be the child's friend anymore. (3) Other children telling nasty stories that were not true about them. (4) Other 
children deliberately spoiling their games. If the child responded that he or she had experienced any of these behaviours, the child was asked to supply a description with examples. This was carried out to ensure that the behaviours had been deliberate and to ascertain that the perpetrator(s) were children that the child normally played with. Children were then asked to express how frequently the incidents occurred in the last 6 months for each of the four questions (seldom: 1-3 times during the past 6 months; frequently: 4 times or more during the past 6 months; very frequently: at least once per week). The four types of relational bullying were then repeated to the child and they were asked whether they had ever used any of the behaviours to upset other children over the past 6 months (never or seldom: 1-3 times during the past 6 months; frequently: 4 times or more during the past 6 months; very frequently: at least once per week).

At no time during the interview was the term "bullying" used. Only behavioural (operational) descriptions were used.

According to the results of the interview, children were classified into the following groups (Whitney \& Smith, 1993; Wolke \& Stanford, 1999) for physical direct bullying and relational bullying, separately: direct bullies (children who were involved in physically bullying others frequently or every week but are never or only rarely physically victimised); direct victims (children who experienced any of the above described behaviours: being called bad/nasty names, being threatened, having belongings stolen, having lies told about them, being hit/beaten, having nasty tricks played on them, frequently or every week but bully others rarely or never); direct bully/ victims (children who both physically bully others and become physical victims of the six described behaviours frequently or every week); direct neutrals who neither physically bully others or become physical victims (never or rarely only).

For relational bullying the classifications were as follows: relational bullies (children who were involved in relationally bullying others frequently or every week but are never or only rarely relationally victimised); relational victims (children who experienced any of the above described behaviours: friends not wanting to play with them, friends withdrawing friendship, friends spreading nasty rumours, friends deliberately spoiling games, frequently or every week but bully others rarely or never); relational bully/victims (children who both relationally bully others and become relational victims frequently or every week); relational neutrals who neither relationally bully others or become relationally victimised (never or rarely only).

Behaviour questionnaire. The Strengths and Difficulties Questionnaire (SDQ) (Goodman, 1997) is a revision and extension of the Rutter Behaviour Questionnaire. Goodman and Scott (1999) and Klasen et al. (in press) have found that the SDQ correlates highly $(>.80)$ with the CBCL total score and discriminates as well as the Rutter Behaviour Scales (Elander \& Rutter, 1996) and the Achenbach (1991) Child Behaviour Checklist (CBCL) between children with clinically significant behaviour problems and no problem behaviour children while offering the following additional advantages: a focus on strengths as well as difficulties; better coverage of inattention, peer relationships, and prosocial behaviour; and a shorter format. The SDQ enquires about 25 attributes, 10 of which would be considered strengths. The 25 SDQ items fall into 5 scales of 5 items each, and tap 5 distinct dimensions: Conduct Problems, Emotional Symptoms, Hyperactivity, Peer Problems, and Prosocial Behaviour. Each item is scored 0-2 in response to "not true", "somewhat true", or "certainly true" and a total score ranging from $0-10$ generated for each subscale by summing the scores for the 5 items that make up the scale. The scores for conduct problems, emotional symptoms, hyperactivity, and peer problems are summed to generate a Total Difficulties Score ranging from $0-40$. For each scale, except for Prosocial, higher scores indicate more problems.

Missing scores were dealt with as follows: if only one item from any subscale was missing, the total was pro-rated, otherwise the subscale and total scale were treated as missing data. The reliability (internal consistency according to Cronbach's alpha) of each subscale and the Total Difficulties scale in this sample was: Total Difficulties .83, Conduct Problems .60, Emotional Symptoms .73, Hyperactivity .80, Peer Problems .56, and Prosocial Behaviour .70.

For categorical analysis Goodman (1997) suggested the following bandings: $80 \%$ of children in the sample are normal, $10 \%$ are borderline, and $10 \%$ ( $>90$ th percentile) are in the clinical range (see Table 2). We reassessed the banding in the current sample according to gender. Whereas the bandings proposed for Conduct Problems, Emotional Problems, Hyperactivity, and Peer Problems were reproduced and did not differ according to gender, different cutoff points were found for the Prosocial Behaviour scales and gender-specific banding for the Total Difficulty Score (Table 2). The current sample cutoff points were used in subsequent analysis.

\section{Statistical Analyses}

First, it was determined whether those who returned the questionnaires differed from those who did not (dropout analysis using chi-square comparisons). Second, differences in SDQ scores according to whether children were bullies, bully/ victims, victims, or neutrals were analysed using one-way ANOVA for direct and relational groups separately. The $p$ value was set at $<.01$ considering the sample size. Effect size (ES) for mean differences is expressed as Cohen's f (Cohen, 1988, pp. 273-288). Contrasts were computed using a posteriori Tukey-HSD test. To determine gender differences and school year differences in direct and relational bullying for each dimension of behaviour, two-way ANOVAs with bullying group by gender or school year were computed, allowing for interactions. Third, chi-square analysis was used to determine differences in relative frequencies of children in the clinical versus normal/borderline (combined) range according to bullying groups.

\section{Results}

\section{Final Sample}

Of the 1982 children who had interviews, 1639 parents returned the SDQ $(82.7 \%$ return rate). Comparisons between those who returned the SDQ $(N=1639)$ and the

Table 2

Bandings for $S D Q$ Subscales

\begin{tabular}{lccc}
\hline & Normal & Borderline & Clinical \\
\hline Total Difficulties score (males) & $0-14$ & $15-17$ & $18-40^{\mathrm{b}}$ \\
Total Difficulties score (females) & $0-12$ & $13-15$ & $16-40^{\mathrm{b}}$ \\
Conduct Problems score & $0-2$ & 3 & $4-10^{\mathrm{a}}$ \\
Emotional Symptoms score & $0-3$ & 4 & $5-10^{\mathrm{a}}$ \\
Hyperactivity score & $0-5$ & 6 & $7-10^{\mathrm{a}}$ \\
Peer Problems score & $0-2$ & 3 & $4-10^{\mathrm{a}}$ \\
Prosocial Behaviour score & $7-10$ & 6 & $0-5^{\mathrm{b}}$ \\
\hline
\end{tabular}

\footnotetext{
${ }^{a}$ Scales which used the same bandings chosen by Goodman (1997).

${ }^{\mathrm{b}}$ Adjusted bandings to provide suggested cutoffs of $80 \%, 10 \%$, and $10 \%$.
} 
Table 3

Comparison of Direct and Relational Bullying for Returned and Nonreturned Questionnaires

\begin{tabular}{|c|c|c|c|c|c|c|}
\hline & \multicolumn{3}{|c|}{ Direct } & \multicolumn{3}{|c|}{ Relational } \\
\hline & $\begin{array}{c}\text { Total } \\
\quad N\end{array}$ & $\begin{array}{c}\text { Returned } \\
(N=1638) \\
(\%)\end{array}$ & $\begin{array}{l}\text { Unreturned } \\
(N=342) \\
(\%)\end{array}$ & $\begin{array}{c}\text { Total } \\
\qquad N\end{array}$ & $\begin{array}{c}\text { Returned } \\
(N=1637) \\
(\%)\end{array}$ & $\begin{array}{l}\text { Unreturned } \\
(N=341) \\
(\%)\end{array}$ \\
\hline Bullies & 96 & 72.9 & 27.1 & 26 & 69.2 & 30.8 \\
\hline Boys & 66 & 71.2 & 28.8 & 21 & 66.7 & 33.3 \\
\hline Girls & 30 & 76.7 & 23.3 & 5 & 80.0 & 20.0 \\
\hline Bully/Victims & 221 & 75.6 & 24.4 & 118 & 81.4 & 18.6 \\
\hline Boys & 164 & 74.4 & 25.6 & 72 & 80.6 & 19.4 \\
\hline Girls & 57 & 78.9 & 21.1 & 46 & 82.6 & 17.4 \\
\hline Victims & 796 & 82.0 & 18.0 & 748 & 83.2 & 16.8 \\
\hline Boys & 419 & 80.9 & 19.1 & 369 & 80.5 & 19.5 \\
\hline Girls & 377 & 83.3 & 16.7 & 379 & 85.8 & 14.2 \\
\hline Neutrals & 867 & 86.3 & 13.7 & 1086 & 83.0 & 17.0 \\
\hline Boys & 368 & 82.9 & 17.1 & 553 & 80.1 & 19.9 \\
\hline Girls & 499 & 88.8 & 11.2 & 533 & 85.9 & 14.1 \\
\hline
\end{tabular}

dropouts $(N=343)$ were computed and characteristics of the potential and final sample are shown in Table 1. There were no differences in return rate according to school year or ethnicity of the children. However, slightly more parents of girls than boys returned questionnaires. Although the difference was small $(<2 \%$ difference between total group and final sample) it was statistically significant, $\chi^{2}(1,1982)=11.59, p<.001$.

\section{Prevalence of Bullying}

Of the 1639 children, $70(4.3 \%)$ were identified as direct bullies-boys : $47(2.9 \%)$; girls: $23(1.4 \%)-167$ $(10.2 \%)$ as bully/victims - boys : $122(7.4 \%)$; girls: 45 $(2.7 \%)$-and $653(39.8 \%)$ as victims - boys: 339 $(20.7 \%)$; girls : $314(19.2 \%)$. The remaining $748(45.6 \%)$ children were neutral (1 child had missing data). Regarding relational bullying, $18(1.1 \%)$ were bulliesboys: $14(0.9 \%)$; girls: $4(0.2 \%)-96(5.9 \%)$ bully/ victims-boys: $58(3.5 \%)$; girls: $38(2.3 \%)$-and 622 $(37.9 \%$ ) victims - boys : $297(18.1 \%)$; girls : $325(19.9 \%)$. The remaining $901(55.0 \%)$ children were neutral $(2$ children had missing data). Participation in direct and relational bullying was found to be partially overlapping: $521(31.8 \%)$ children-boys: $290(35.7 \%)$; girls: 231 $(28.0 \%)$ - were identified as being involved in both direct and relational bullying behaviour (physical bullies, bully/ victims or victims and also either relational bullies, bully/victims or victims). A further 369 children (22.5\%) were involved in physical bullying only and were classified as relational neutrals-boys: $218(26.8 \%)$; girls: 151 $(18.3 \%)-215(13.1 \%)$ were involved in relational bullying and were physical neutrals-boys: 79 (9.7\%); girls: $136(16.5 \%)$-and $532(32.5 \%)$ were not involved in any bullying behaviour (physical neutrals and relational neutrals). Full results on the prevalence and distinctiveness of relational bullying are reported elsewhere (Wolke \& Karstadt, 1999).

\section{Bullying and Returned Questionnaires}

It was determined whether there were differences in return rates for questionnaires according to direct and relational bullying status (Table 3 ). Chi-square analysis on direct bullying identified significantly more bullies and bully/victims among children for whom questionnaires were not returned, compared with children for whom questionnaires were returned, $\chi^{2}(3,1980)=22.30$, $p<.000$, although this was not significant when analysed by gender. Parents of victims and neutrals were thus more likely to return the behaviour questionnaires than those of bullies or bully/victims.

Chi-square analysis on relational bullying showed no significant difference between children for whom questionnaires were returned, compared with children for whom questionnaires were not returned. There were also no differences between boys and girls (Table 3 ).

\section{Behaviour Differences between Bullies, Victims, Bully/Victims, and Neutral Children}

Direct bullying. One-way ANOVA between bullies, victims, bully/victims and neutral direct bullying and the behaviour subscales found significant differences on all behaviour scales save Emotional Symptoms: Total Difficulties, $F(3,1622)=20.50, p<.001$, $(\mathrm{ES}=.19)$; Conduct Problems, $F(3,1633)=26.14, p<.001$, $(\mathrm{ES}=.22)$; Hyperactivity, $F(3,1630)=23.78, p<.001$, $(\mathrm{ES}=.21)$; Peer Problems, $F(3,1627)=9.60, p<.001,(\mathrm{ES}=.13)$ and Prosocial Behaviour, $F(3,1633)=8.77, p<.001$, $(\mathrm{ES}=.13)$. The mean scores are shown for the Total Difficulty and the subscales in Figs. 1 to 3.

A posteriori contrasts (Tukey HSD test) indicated that each group involved in bullying had significantly higher scores than neutrals (bullies $M=10.32$, bully/victims $M=10.59$, victims $M=9.63$ vs. neutrals $M=7.67$ ) on the Total Difficulties Scores (Fig. 1). Similarly, each group involved in bullying had significantly higher scores than neutrals on the Conduct scale (bullies $M=2.13$, bully/victims $M=2.23$, victims $M=1.72$ vs. neutrals $M=1.23$ ) (Fig. 3). Furthermore, bully/victims had higher reported conduct problems scores than victims (bully/victim $M=2.33$ vs. victim $M=1.72$ ). All groups involved in bullying had significantly higher scores than neutrals on the Hyperactivity scale (bullies $M=4.39$, bully/victims $M=4.55$, victims $M=3.88$, neutrals $M=$ 


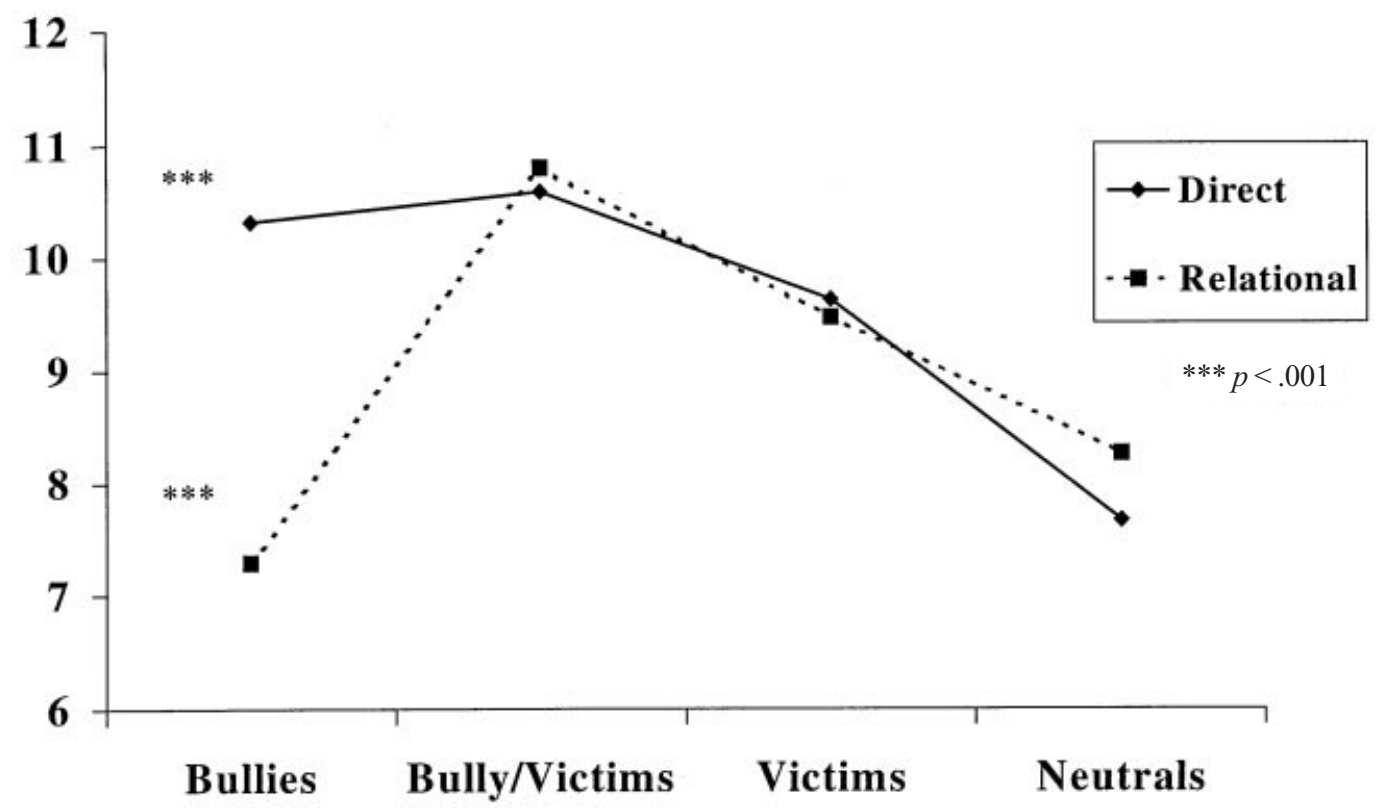

Figure 1. Average Total Difficulties scores from the Strengths and Difficulties Questionnaire for different bullying groups involved in direct and relational bullying.

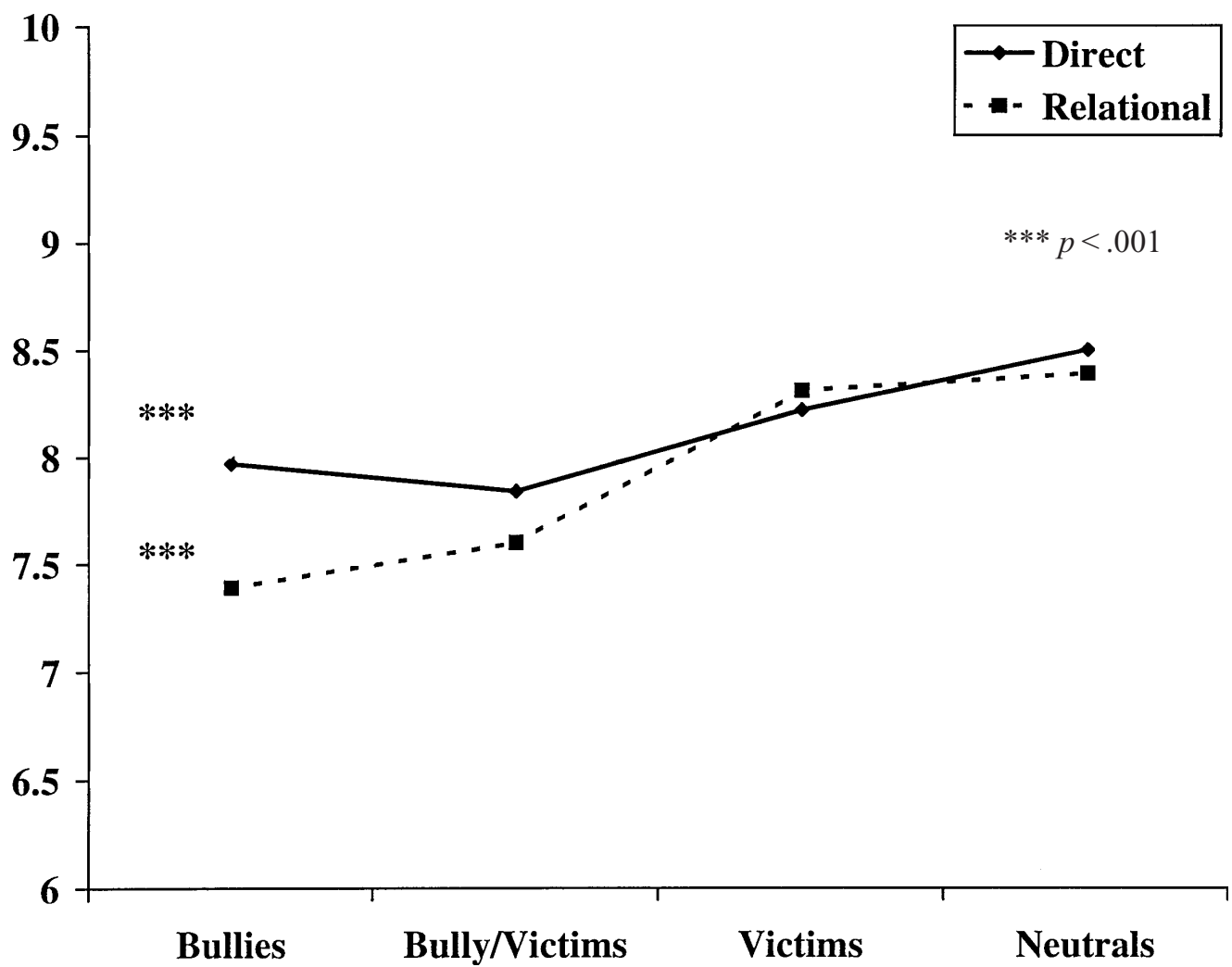

Figure 2. Average Prosocial Behaviour scores from the Strengths and Difficulties Questionnaire for different bullying groups involved in direct and relational bullying.

3.06) (Fig. 3). Victims had significantly higher scores than neutrals on the Peer Problems scale (bullies $M=1.77$, bully/victims $M=1.78$, victims $M=1.85$, neutrals $M=$ 1.38) (Fig. 3). The contrast between bullies, bully/victims, and neutrals failed to reach significance. On the Prosocial Behaviour scale only bully/victims had significantly lower scores than neutrals (bullies $M=7.97$, bully/ victims $M=7.84$, victims $M=8.22$, neutrals $M=8.50$ ) (Fig. 2). All contrasts were significant at $p<.01$ or less. There were no significant mean differences between bully subgroups for Emotional Symptoms (bullies $M=2.01$, bully/victims $M=2.03$, victims $M=2.22$, neutrals $M=$ 1.99).

Relational bullying. Scores on all behaviour scales except for emotional symptoms were found to differ significantly according to bullying group: Total Difficulties, $F(3,1621)=9.35, p<.001$, $(\mathrm{ES}=.13)$; Conduct Problems, $F(3,1632)=10.12, p<.001$, $(\mathrm{ES}=.14)$; Hyperactivity, $F(3,1629)=6.75, p<.001,(\mathrm{ES}=.11)$; Peer problems, $F(3,1626)=6.76, p<.001,(\mathrm{ES}=.11)$ 


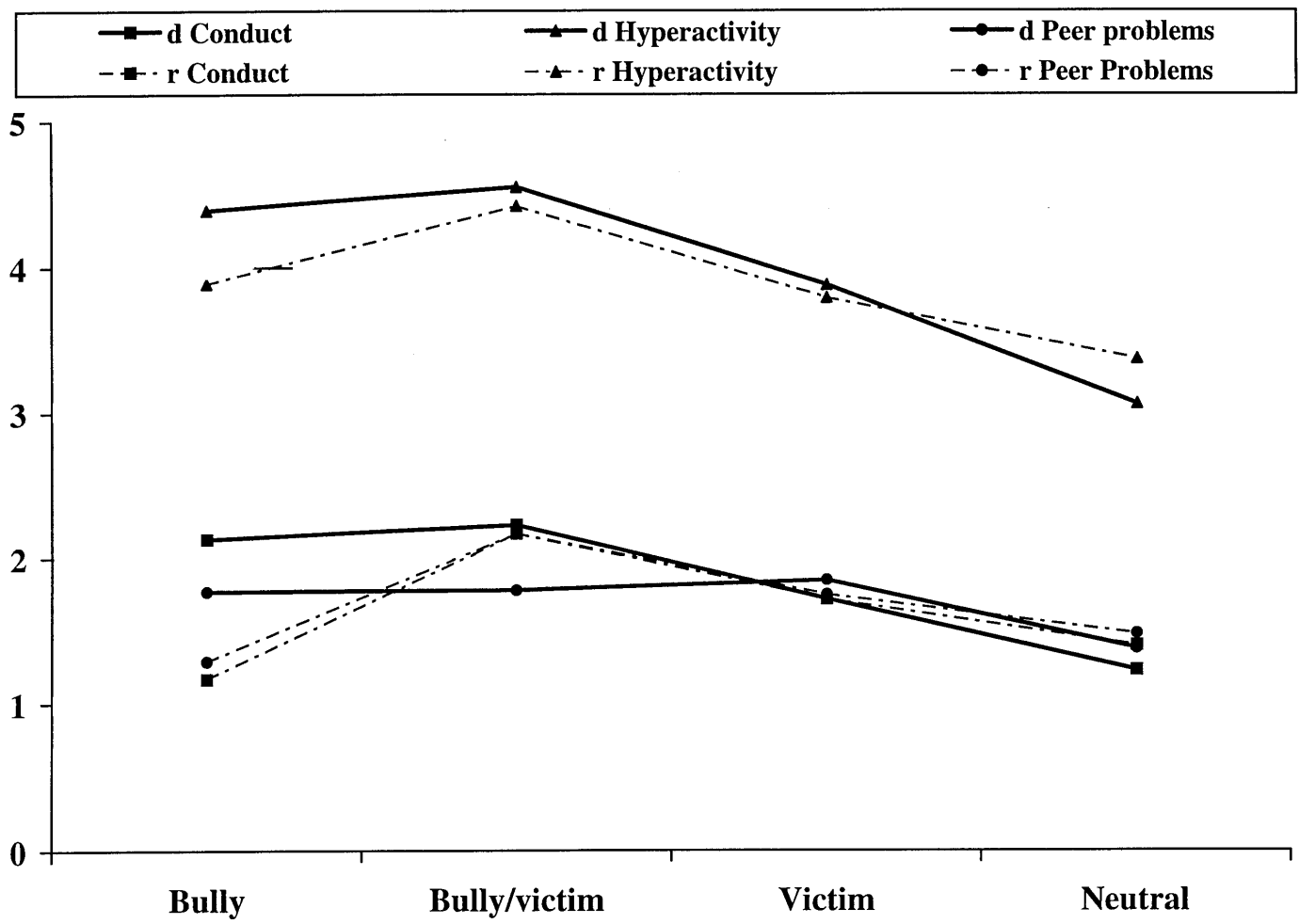

Figure 3. Average Conduct Problem scores, Hyperactivity scores, and Peer Problem scores from the Strengths and Difficulties Questionnaire for different bullying groups involved in direct (d) and relational (r) bullying. All were significant at $p<.001$.

and Prosocial Behaviour, $F(3,1632)=7.73, p<.001$, $(\mathrm{ES}=.12)($ see Figs. 1 to 3 ).

The a posteriori contrasts $(p<.01)$ showed that bully/victims and victims had significantly higher scores than neutrals on the Total Difficulties scale (bullies $M=$ 7.29, bully/victims $M=10.80$, victims $M=9.48$, neutrals $M=8.26$ ). The contrast between bullies and neutrals was not significant, although bullies had the lowest Total Difficulties score. Similarly, bully/victims and victims had significantly higher scores than neutrals on the Conduct Problems scale (bullies $M=1.17$, bully/ victims $M=2.17$, victims $M=1.72$, neutrals $M=1.40$ ). Only bully/victims differed significantly from neutrals on the Hyperactivity scale (bullies $M=3.89$, bully/victims $M=4.42$, victims $M=3.79$, neutrals $M=3.37$ ) and the Peer Problems scale (bullies $M=1.29$, bully/victims $M=2.17$, victims $M=1.75$, neutrals $M=1.48$ ). In all these subscales bullies did not differ from the neutrals. In contrast, on the Prosocial Behaviour scale bullies and bully/victims had significantly lower scores than victims and neutrals (bullies $M=7.39$, bully/victims $M=7.60$, victims $M=8.31$, neutrals $M=8.39$ ). There was no difference in the scores between victims and neutrals. There were no significant differences between relational bully subgroups for Emotional Symptoms (bully, $M=$ 1.22 , bully/victims $M=2.05$, victims $M=2.22$, neutrals $M=2.01)$.

Gender, age, bullying, and behaviour problems. The two-way ANOVAs (bullying group by gender) found boys to have significantly higher scores than girls on Hyperactivity, $F(1,1630)=20.97, p<.001$ (boys $M=$ 4.20, girls $M=2.30$ ) and lower scores in prosocial behaviour, $F(1,1633)=22.82, p<.001$ (boys $M=7.94$, girls $M=8.66)$. There were no significant gender differences for Total Difficulties (boys $M=9.63$, girls $M=8.11$ ), Conduct Problems (boys $M=1.77$, girls $M=1.36$ ), Emotional Symptoms (boys $M=2.02$, girls $M=2.15$ ), or for Peer Problems (boys $M=1.64$, girls $M=1.61$ ).
There were no interaction effects between direct bullying group and gender on any of the behaviour scales.

Two-way ANOVAs (relational bullying by gender) found boys to have significantly higher scores than girls on Hyperactivity, $F(1,1629)=7.63, p<.01$ (boys $M=$ 4.20, girls $M=2.30$ ) and lower scores on Prosocial Behaviour, $F(1,1632)=17.40, p<.001$ (boys $M=7.94$, girls $M=8.66)$. There were no significant gender differences for Total Difficulties (boys $M=9.63$, girls $M=$ 8.11), Conduct Problems (boys $M=1.77$, girls $M=$ 1.36), Emotional Symptoms (boys $M=2.02$, girls $M=$ 2.15 ), or Peer Problems (boys $M=1.64$, girls $M=1.61$ ) once relational bullying group membership had been considered.

No differences in behaviour scores were detected according to school year or interactions with direct or relational bullying group on parent reports of child behaviour in the SDQ.

Differential effects of direct and relational bullying. As shown in Figs. 1-3, no differences in mean scores in any of the behaviour scales were found between direct vs. relational bully/victims, direct vs. relational victims, or those neutral in direct or relational bullying. In contrast, the behaviours of those children who were direct vs. relational bullies differed on Total Difficulties. Conduct Problems, and Hyperactivity. Relational bullies had lower scores in these scales than direct bullies. A formal statistical test was not indicated as group membership was partly overlapping (see below).

\section{Bullying and Behaviour Problems in the Clinical Range}

It was tested whether those involved in bullying differed from neutrals in the relative frequency of behaviour problems in the clinical range. First, overall four group comparisons were computed and then individual comparisons made contrasting each bullying subgroup to 
Table 4

Direct Bullying_Clinical Group above 90th Percentile Expressed as a Percentage $(N=1622-1633)$

\begin{tabular}{|c|c|c|c|c|c|c|c|c|}
\hline & \multicolumn{2}{|c|}{ Bullies } & \multicolumn{2}{|c|}{ Bully/Victims } & \multicolumn{2}{|c|}{ Victims } & \multicolumn{2}{|c|}{ Neutrals } \\
\hline & $\%$ & $N$ & $\%$ & $N$ & $\%$ & $N$ & $\%$ & $N$ \\
\hline Total Difficulties & $13.2 * * *$ & 68 & 18.6 & 167 & 14.2 & 648 & 6.9 & 739 \\
\hline Conduct Problems & $18.6^{* * *}$ & 70 & 24.6 & 167 & 14.9 & 650 & 7.2 & 746 \\
\hline Hyperactivity & $29.0 * * *$ & 69 & 22.8 & 167 & 17.2 & 650 & 9.3 & 744 \\
\hline Emotional Symptoms & 12.9 & 70 & 13.8 & 167 & 16.3 & 651 & 12.8 & 745 \\
\hline Peer Problems & $14.5^{* *}$ & 69 & 13.2 & 167 & 17.8 & 650 & 10.8 & 741 \\
\hline Prosocial Behaviour & $12.9^{* *}$ & 70 & 13.9 & 166 & 9.8 & 651 & 5.9 & 746 \\
\hline
\end{tabular}

$* * p<.01 ; * * * p<.001$.

Table 5

Relational Bullying-Clinical Group above 90th Percentile Expressed as a Percentage $(N=1621-1632)$

\begin{tabular}{|c|c|c|c|c|c|c|c|c|}
\hline & \multicolumn{2}{|c|}{ Bullies } & \multicolumn{2}{|c|}{ Bully/Victims } & \multicolumn{2}{|c|}{ Victims } & \multicolumn{2}{|c|}{ Neutrals } \\
\hline & $\%$ & $N$ & $\%$ & $N$ & $\%$ & $N$ & $\%$ & $N$ \\
\hline Total Difficulties & $5.9 * * *$ & 17 & 20.8 & 96 & 13.4 & 618 & 8.9 & 890 \\
\hline Conduct Problems & $5.6 * * *$ & 18 & 22.9 & 96 & 15.0 & 620 & 9.9 & 898 \\
\hline Hyperactivity & 16.7 & 18 & 19.8 & 96 & 15.5 & 618 & 13.5 & 897 \\
\hline Emotional Symptoms & 0.0 & 18 & 12.5 & 96 & 15.3 & 620 & 13.9 & 898 \\
\hline Peer Problems & 0.0 & 17 & 21.9 & 96 & 15.0 & 620 & 12.8 & 893 \\
\hline Prosocial Behaviour & $22.2 * *$ & 18 & 16.8 & 95 & 9.0 & 620 & 7.1 & 899 \\
\hline
\end{tabular}

$* * p<.01 ; * * * p<.001$.

neutrals (Table 4). This chi-square analysis identified significantly more direct bully/victims and victims in the clinical group on Total Difficulties, $\chi^{2}(3,1622)=28.78$, $p<.001$ (Table 4). This was found for girls, $\chi^{2}(3,812)=$ $18.77, p<.001$, but failed to reach significance for boys, $\chi^{2}(3,810)=8.16, p>.01$. Significantly more bully/ victims showed Conduct Problems, $\chi^{2}(3,1633)=46.73$, $p<.001$ and this was found for girls, $\chi^{2}(3,820)=21.54$, $p<.001$, and boys alike, $\chi^{2}(3,813)=18.41, p<.001$. Significantly more bullies and bully/victims were in the clinical range in Hyperactivity, $\chi^{2}(3,1630)=40.74$, $p<.001$, and this was found for girls, $\chi^{2}(3,818)=14.56$, $p<.01$, and boys, $\chi^{2}(3,812)=14.64, p<.01$. For Peer Problems, there were significantly more victims identified in the clinical group, $\chi^{2}(3,1627)=14.40, p<.01$, but this was not significant when analysed for girls and boys separately. On the Prosocial scale more bully/victims were in the clinical group, $\chi^{2}(3,1633)=15.67, p<.01$ (Table 4), but this was not significant when tested for girls and boys separately. No differences were found for Emotional Symptoms.

Chi-square analysis for relational bullying identified fewer significant differences between groups, although the tendencies were similar to direct bullying. Significantly more bully/victims and victims were in the clinical range for Total Difficulties, $\chi^{2}(3,1621)=17.23, p<.001$ (Table 5), and this was not found when analysed separately by gender. For Conduct Problems there were significantly more bully/victims who scored above the 90 th percentile, $\chi^{2}(3,1632)=19.27, p<.001$ (Table 5), and this was found for boys only when analysed according to gender, $\chi^{2}(3,812)=14.88, p<.01$. For Prosocial Behaviour there were significantly more bullies and bully/victims in the clinical range, $\chi^{2}(3,1633)=$ $15.5, p<.01$ (Table 5$)$, but this was not significant when tested for boys and girls separately. No significant differences were found between relational bullying groups on measures of Emotional Symptoms, Hyperactivity, or Peer Problems.

No differences were found between Year 2 and Year 4 children on any scale of behaviour problems in the clinical range for either direct or relational bullying.

\section{The Differential Effects of Children Involved in Either Direct or Relational Bullying or Both Direct and Relational Bullying}

Children who were involved in both types of bullying behaviour, i.e. direct bullies, bully/victims, or victims and also relational bullies, bully/victims, or victims $(N=516)$ were then compared with children who were not involved in either type of bullying i.e. direct neutrals and relational neutrals $(N=523)$, children who were involved in direct bullying only $(N=367)$, and children who were involved in relational bullying only $(N=215)$. For Total Difficulties, $\chi^{2}(3,1621)=30.77, \quad p<.001$, and Conduct Problems, $\chi^{2}(3,1632)=39.03, p<.001$, there were significantly more children in the clinical range who were involved in both direct and relational bullying compared to children who were involved in only one type of bullying or no bullying (Fig. 4). For Hyperactivity, $\chi^{2}(3,1629)=$ $31.69, p<.001$, and Peer Problems, $\chi^{2}(3,1626)=12.39$, $p<.01$, significantly more children were in the clinical range who were involved in both types of bullying or direct bullying only compared to those who were involved in relational bullying only or no bullying (Fig. 4). Similarly, for prosocial behaviour, those children in the clinical range were more likely to be involved in both types of bullying behaviour, $\chi^{2}(3,1632)=14.37, p<.01$. No significant differences were found for emotional symptoms.

The ANOVAs showed similar differences for all behaviour subscales excluding emotional symptoms ac- 


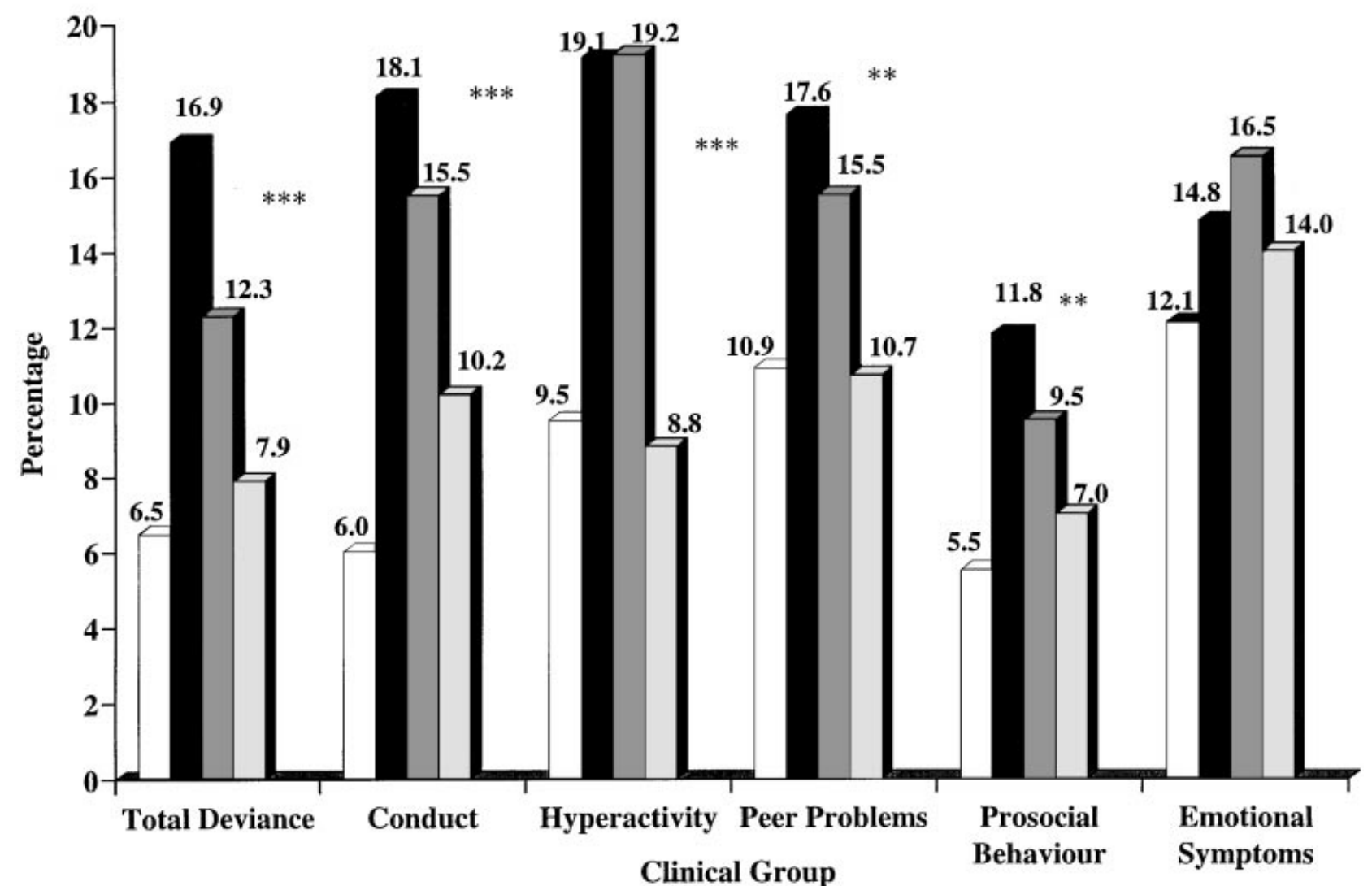

Figure 4. The percentage of children in the clinical range for behaviour problems involved in direct bullying, relational bullying, or both types of bullying $(* * p<.01 ; * * * p<.001)$.

cording to whether the child was involved in direct bullying only, relational bullying only, both direct and relational bullying, or neutral: Total Difficulties, $F(3,1621)=21.37, \quad p<.001, \quad(\mathrm{ES}=.20) ; \quad$ Conduct Problems, $\quad F(3,1632)=22.49, \quad p<.001, \quad(\mathrm{ES}=.20)$; Hyperactivity, $F(3,1629)=21.02, p<.001$, $(\mathrm{ES}=.19)$; Peer Problems, $F(3,1626)=11.34, p<.001,(\mathrm{ES}=.14)$; and Prosocial Behaviour, $F(3,1632)=6.76, p<.001$, $(\mathrm{ES}=.12)$

Post hoc analyses $(p<.01)$ revealed that children received significantly higher total deviancy behaviour scores, conduct scores, and hyperactivity scores if they were involved in both types of bullying or direct bullying compared to neutral and children involved in relational bullying: Total Deviancy (both types: $M=10.13$; direct: $M=9.49$; neutral: $M=7.39$; relational: $M=8.33)$; Conduct (both types: $M=1.91$; direct: $M=1.75$; neutral: $M=1.16$; relational: $M=1.41)$; Hyperactivity (both types: $M=4.16$; direct: $M=3.88$; neutral: $M=$ 3.01 ; relational: $M=3.19$ ). Children had significantly more peer problems if they were involved in both types of bullying or direct bullying compared to neutral children: (both types: $M=1.89$; direct: $M=1.74$; neutral: $M=$ 1.30). Children involved in both types of bullying had significantly lower Prosocial scores than children not involved in bullying behaviour: (both: $M=8.08$; neutral: $M=8.51)$.

\section{Discussion}

The present study investigated the prevalence of direct and relational bullying and associated behaviour problems among primary school children in the U.K.
With regards to the prevalence of direct bullying, similar proportions of boys and girls were classified as direct "pure" victims, which supports previous findings by Bentley and Li (1995), Farrington (1993), and Whitney and Smith (1993). Conversely, Boulton and Underwood (1992), Genta et al. (1996), Kumpulainen et al. (1998), and Wolke and Stanford (1999) found that males were victimised more frequently than females. More boys were classified as direct "pure" bullies and substantially more boys were classified as direct bully/victims compared to girls. This finding substantiates research findings that boys are more overtly aggressive (Caloust Gulbenkian Foundation, 1995; Farrington, 1993; Olweus, 1994; Wolke \& Stanford, 1999).

Similar levels of "pure" relational victims to "pure" direct victims were found and proportions were comparable for boys and girls. The frequency of "pure" relational bullies and relational bully/victims was lower compared to direct bullying. A prominent finding is the extremely low number of girls who were classified as "pure" relational bullies and relational bully/victims compared to boys. This finding disputes the results by Crick, Casas, and Hyon-Chin (1999), Crick and Grotpeter (1995), and Schäfer, Wellman, and Crick (2000) that boys and girls are equally aggressive if both direct and relational bullying is taken into account. Instead the findings support those by Craig (1998), Lagerspetz and Björkqvist (1994), and Roecker, Caprini, Dickerson, Parks, and Barton (1999) that young boys are just as likely or more likely to be involved in relational bullying. Similarly to Craig (1998), this study did not find age differences in relation to relational aggression (Lagerspetz, Björkqvist, \& Peltonen, 1988) or behaviour 
Table 6

Average Scores on the Strengths and Difficulties Questionnaire for Children Involved in No Bullying, Both Types of Bullying, or Direct Bullying or Relational Bullying Only $(N=1621-1632)$

\begin{tabular}{|c|c|c|c|c|}
\hline & Direct and relational & Direct only & Relational only & Neutrals \\
\hline & Mean $(S D)$ & Mean $(S D)$ & Mean $(S D)$ & Mean $(S D)$ \\
\hline Total Difficulties*** & $10.13(6.35)$ & $9.49(6.17)$ & $8.33(5.42)$ & $7.39(5.12)$ \\
\hline Conduct Problems*** & $1.91(1.78)$ & $1.75(1.71)$ & $1.41(1.40)$ & $1.16(1.31)$ \\
\hline Hyperactivity*** & $4.16(2.66)$ & $3.88(2.77)$ & $3.19(2.29)$ & $3.01(2.35)$ \\
\hline Emotional Symptoms & $2.18(2.32)$ & $2.15(2.29)$ & $2.17(2.19)$ & $1.91(1.99)$ \\
\hline Peer Problems *** & $1.89(1.84)$ & $1.74(1.73)$ & $1.56(1.66)$ & $1.30(1.53)$ \\
\hline Prosocial Behaviour *** & $8.08(1.82)$ & $8.21(1.76)$ & $8.48(1.74)$ & $8.51(1.57)$ \\
\hline
\end{tabular}

$* * * p<.001$.

problems. The present findings may be explained in light of methodological and theoretical assertions: most previous studies have employed anonymous self-report questionnaires to determine the prevalence of bullying rather than individual interviews. One explanation may be that girls have superior social cognitive skills than boys (Skuse, 1997) and were able to perceive and give desirable answers to the interviewers, therefore resulting in low rates of relational bullying among girls. Alternatively, boys may endorse bullying behaviour and thus report it more often. Another likely account refers to developmental theories that bullying follows three main stages: (1) direct physical; (2) direct verbal during the preschool years; (3) indirect/relational bullying at secondary school age (Björkqvist, Lagerspetz, \& Kaukiainen, 1992; Rivers \& Smith, 1994). Rotenberg (1985) carried out a developmental study with 6-12-year-olds and found that relational aggression became more common in middle childhood, and Lagerspetz and Björkqvist (1994) suggest that younger girls may use direct forms of aggression in terms of physical and verbal behaviour and then shift their behaviour towards relational bullying once their social skills are more advanced, which occurs ahead of boys. Thus in adolescence, but not among young primary school children between 6-9 years, as found here, more girls are involved in relational bullying (Craig, 1998; Lagerspetz \& Björkqvist, 1994).

Analyses regarding the association between bullying rates and returned parent questionnaires elicited a bias for children involved in direct bullying but not relational bullying. The parents of boys and girls who were classified as direct bullies or direct bully/victims were less likely to return the behaviour questionnaires than if their child had been classified as a direct victim or neutral. These results suggest that parents were aware that their child was bullying children from teacher feedback or behaviour exhibited at home and thus did not want to return the questionnaire. Relational bullying, which is more subtle and complex in nature, may be concealed at home and in schools, hence parents did not hesitate in returning the parent questionnaire. An alternative explanation is that parents of children involved in direct bullying are simply less inclined to be cooperative. Families of bullies and bully/victims are more often characterised by dysfunctional mechanisms, lack of positive communication (Batsche \& Knoff, 1994; Lowenstein, 1977), and lack of a father figure (Bowers, Smith, \& Binney, 1994; Rigby, 1994), or the fathers of bullies have often been bullies themselves (Farrington, 1995). Previous research on study dropouts have found more developmental problems in children of families who decided not to continue to participate in behavioural research (Wariyar \& Richmond, 1989; Wolke, Söhne, Ohrt, \& Riegel, 1995). The behaviour problem rates reported here for direct bullies and bully/victims are likely to be underestimations of true rates.

A key finding is that behaviour problem ratings of parents for children involved in direct bullying according to individual interviews with the children were increased. All groups involved in direct bullying had significantly higher scores than neutral children on total difficulties, conduct problems, and hyperactivity and lower scores than neutral children for prosocial behaviour. Bully/ victims and victims had more parent-reported peer problems than neutrals. The effect sizes were moderate (Cohen, 1988) for total deviancy, hyperactivity, and conduct problems and small for peer problems or lack of prosocial behaviour. These findings held up when the relative frequencies of children in the clinical range on the SDQ were compared. Overall, direct bully/victims were the most behaviourally disturbed. They were 2.7 times more likely to have any behaviour problems than neutrals; they were 3.4 times more likely to be conduct disordered and 2.5 times more likely to be hyperactive compared to children not involved in direct bullying. Our findings replicate those reported by Kumpulainen et al. (1998) in a Finnish cohort. They also found that all groups involved in direct bullying were more psychologically disturbed and bully/victims had more externalising and hyperactivity problems according to parent and teacher reports. It is notable that direct bully/victims had, apart from hyperactivity problems, consistently more behavioural problems than "pure" bullies (Austin \& Joseph, 1996; Kumpulainen et al., 1998; Mynard \& Joseph, 1997). Boulton and Smith (1994) proposed that bully/victims have irritative tendencies such as hyperactivity in class, which then provokes bullying behaviour both as a bully and a victim. Bully/victims who are likely to be provocative, who become victimised and torment others at other times, and who show a range of behaviour problems seem to match the picture of the rejected aggressive child (Coie, Dodge, Terry, \& Wright, 1991; Farrington, 1995; Loeber \& Hay, 1994; Schwartz, Dodge, Pettit, \& Bates, 1997). Social cognition skills may also be interrelated with the finding that bully/victims suffer from the greatest degree of behaviour problems (Sutton \& Smith, 1999). Besag (1989), Dodge (1986), and Feldman and Dodge (1987) report that aggressive or conduct disordered children use few social cues to interpret social situations and hence 
attribute hostile intent to peers by repeatedly using aggression to obtain goals. Bully/victims and bullies who showed the highest rates of hyperactive and conduct problems and the least prosocial behaviour at this young age are likely to be at increased risk for life-persistent antisocial behaviour (Lahey, Waldman, \& McBurnett, 1999; Moffitt, Caspi, Harkness, \& Silva, 1993). However, the significant associations between bullying others and externalising problems and hyperactivity should not distract from the finding that most bullies and bully/ victims were not rated as either clinically hyperactive or conduct disordered. This suggests that bullying forms part of the externalising behaviour spectrum but cannot be equated with conduct problems. Bullying occurs in the specific social setting of schools with a defined peer group and is likely to be influenced by multiple family and school factors (Baldry \& Farrington, 1998; Bowers et al., 1994; Fergusson, Horwood, \& Lawton, 1990; MyronWilson, 1999; Myron-Wilson \& Smith, 1997; Rigby, 1994).

A further notable finding replicating results of Kumpulainen et al. (1998) and Schwartz et al. (1998) is that victims have more externalising and hyperactivity problems than those not involved in any bullying behaviour. In contrast, neither victims nor bullies and bully/victims were reported to have more emotional problems compared to neutrals. Schwartz et al., who also asked mothers (and teachers) to report on victims' behaviour, found victimisation by peers to be more strongly associated with externalising/undercontrolled behaviour problems than internalising/overcontrolled difficulties. Previous victimisation research has mainly used self-reports to assess internal difficulties (e.g. Austin \& Joseph, 1996; Salmon et al., 1998; Slee, 1994). Selfreports versus parent reports do not yield identical information (e.g. Achenbach, 1991; Achenbach, McConaughy, \& Howell, 1987). Emotional problems appear to be less reliably reported by external sources than by the children themselves. Schwartz et al. (1998) speculated that one potential implication of these findings is that parents may not always be aware of the psychological distress experienced by bullied children (Smith, 1991). These children may be unlikely to display observable signs of negative reactions (e.g. being more tearful) to their peer group. Kumpulainen et al. (1998), who employed parent, teacher, and self-reports of behaviour, in contrast, found that victims have not only more externalising and hyperactivity problems but also more internalising problems as reported by parents, teachers, and the children themselves. This may be due to the fact that Kumpulainen et al. only considered children as victims if at least two data sources (self, teacher, or parents) identified the child as such. Thus, the informants were aware of the bullying and victimisation status of the child, which was not the case for all parents of victims in our sample (Wolke \& Karstadt, 1999). A sizeable minority of victims suffer in silence, i.e. do not tell their parents (Smith, 1991; Whitney \& Smith, 1993).

The finding that "pure" victims and bully/victims suffer from increased peer problems compared to neutrals is not surprising in the light of previous research. Victims are often described as lonely, immature children who have poor communication and problem-solving skills (McClure \& Sirataki, 1989; Olweus, 1999) and have a dislike of school (Kochenderfer \& Ladd, 1996). From these previous observations and the findings for hyperactivity and externalising problems, it would appear that victims have personality characteristics that make them vulnerable to attacks from stronger, more assertive peers (Egan \& Perry, 1998).

The finding that children who are involved in relational bullying also suffer from increased behaviour problems, including conduct problems, is new. The pattern of results for direct and relational bullying were similar but less pronounced in their effects for relational bullying. Again, relational bully/victims showed the most behaviour problems in the clinical range. However, a number of important differences compared to direct bullying were detected. Whereas males and females involved in direct bullying had similar levels of behaviour problems within the clinical range, more females were within the clinical range for total difficulties and more males were within the clinical range for conduct problems when relational bullying was considered. Furthermore, "pure" relational bullies had the lowest rates of behaviour problems of all children while at the same time they were the least prosocial in their behaviour.

Social cognition theories may proffer an explanation for this finding. Recent studies on theory of mind by Sutton and Smith (1999) and Sutton, Smith, and Swettenham (1999) have reported, contrary to the widespread conception that bullies lack social skills and understanding, that "pure" bullies are superior to any other subgroup involved in bullying in their ability to read the minds of others, thus enabling them to be manipulative and domineering. With regards to "pure" bullies displaying poor prosocial skills, Rigby (1993) reported that bullies have high levels of psychoticism, which leaves them open to being "emotionless manipulators". Furthermore, "theory of mind" has been suggested as a key determinant of self-organisation, which is said to be acquired during the child's early social relationships. Caregiver's ability to communicate understanding of children's intentions at a young age has been proposed as a model for the development of selforganisation (Fonagy \& Target, 1997). Early childhood attachment difficulties with caregivers may offer an explanation for our finding that relational bullies were the least prosocial of all the children in the sample. To be a relational bully requires subtle, careful planning by means of competent social skills and, at the same time, ruthless implementation.

A further new finding offered by the present study relates to the differential effects of children involved in either direct or relational bullying or both direct and relational bullying. A substantial number of children involved in relational bullying were also in one way or another involved in direct bullying behaviour. As reported elsewhere (Wolke \& Karstadt, 1999), relational and direct bullying behaviour are only partly distinct constructs, contrary to findings reported by Crick and Grotpeter (1995). Those children involved in both direct and relational bullying behaviour were at the highest overall risk of behaviour problems, closely followed by those involved in direct bullying only. Those children involved in relational bullying only were comparable to neutral children on most dimensions, particularly for peer problems, although neutral children still had the lowest amount of behavioural problems within the clinical range, at least at primary school age.

The current study, using contemporaneous assessments of bullying and behaviour, is unable to answer the question whether behaviour difficulties lead to bullying behaviour or victimisation or vice versa. Only prospective 
studies starting in infancy, involving family and early peer relationships, can provide answers to this question. Nevertheless, the results reported here have a number of implications for conceptions about those involved in bullying, future research on bullying, and intervention programmes relating to bullying and behaviour problems. First, research is called for that utilises selfreport measures of behaviour problems concurrently with teacher and parental reports of behaviour. Second, more studies are needed which consider relational bullying in terms of behaviour problems and not just peer adjustment problems (Crick, 1996, 1997; Crick \& Bigbee, 1998; Crick, Casas, \& Mosher, 1997; Crick \& Grotpeter, 1995, 1996). Third, these and findings by others suggest that victims may not only be more emotionally disturbed but also often have externalising problems, making them more likely targets of repeated victimisation. Fourth, children who are involved in both direct and relational bullying or direct bullying only are at increased risk of behaviour problems. A particular high-risk group are those children who are bully/victims. Considering that this is already found at primary school age, children who are involved in bullying and show externalising and hyperactivity problems may be at particular risk for lifepersistent conduct disorder (Moffitt et al., 1993). Only follow-up studies, mostly lacking so far, are able to provide definitive answers. Fifth, intervention programmes may need to be tailored differently for those involved in relational bullying only, those involved in both direct and relational bullying, and those with associated behaviour problems that affect the peer group, parenting, and teaching.

Acknowledgements - The study was supported by a project grant from the Economic and Social Science Research Council (ESRC) (award No. R000222563). We would like to thank our co-workers and interviewers who contributed to the study: Katherine Stanford, Anna Marsden, and Tina Gutbrod. We are indebted to the head teachers, teachers, the children, and their parents who made this study possible.

\section{References}

Achenbach, T. (1991). Manual for the Child Behaviour Checklist/4-18 and 1991 profile. Burlington, VT: University of Vermont, Department of Psychiatry.

Achenbach, T., McConaughy, S., \& Howell, C. (1987). Child/ adolescent behavioural and emotional problems: Implications of cross-informant correlations for situational specificity. Psychological Bulletin, 101, 213-232.

Austin, S., \& Joseph, S. (1996). Assessment of bully/victim problems in 8 to 11 year olds. British Journal of Educational Psychology, 66, 447-456.

Baldry, A. C. (1998). Bullying among Italian middle school students. School Psychology International, 19, 361-374.

Baldry, A. C., \& Farrington, D. P. (1998). Parenting influences on bullying and victimisation. Legal and Criminological Psychology, 3, 237-254.

Batsche, G. M., \& Knoff, H. M. (1994). Bullies and their victims: Understanding a pervasive problem in the schools. School Psychology Review, 23, 165-174.

Bentley, K. M., \& Li, A. K. F. (1995). Bully and victim problems in elementary schools and students' beliefs about aggression. Canadian Journal of School Psychology, 11, 153-165.

Besag, V. (1989). Bullies and victims at school. Milton Keynes, U. K.: Open University Press.
Birleson, P. (1981). The validity of depression disorder in childhood and the development of a self-rating scale: A research report. Journal of Child Psychology and Psychiatry, 22, 73-88.

Björkqvist, K., Lagerspetz, K. M. J., \& Kaukiainen, A. (1992). Do girls manipulate and boys fight? Developmental trends in regard to direct and indirect aggression. Aggressive Behaviour, 18, 117-127.

Boulton, M. J. (1993). Aggressive fighting in British middle school children. Educational Studies, 19, 19-39.

Boulton, M. J., \& Smith, P. K. (1994). Bully/victim problems in middle-school children: Stability, self-perceived competence, peer perceptions and peer acceptance. British Journal of Developmental Psychology, 12, 315-329.

Boulton, M. J., \& Underwood, K. (1992). Bully/victim problems among middle school children. British Journal of Educational Psychology, 62, 73-87.

Bowers, L., Smith, P. K., \& Binney, V. (1994). Perceived family relationships of bullies, victims and bully/victims in middle childhood. Journal of Social and Personal Relationships, 11, 215-232.

Byrne, B. J. (1994). Bullies and victims in a school setting with reference to some Dublin schools. The Irish Journal of Psychology, 15, 574-586.

Callaghan, S., \& Joseph, S. (1995). Self-concept and peer victimization among schoolchildren. Personality and Individual Differences, 18, 161-163.

Calouste Gulbenkian Foundation. (1995). Children and violence (1st ed.). London: Author.

Cohen, J. (1988). Statistical power analysis for the behavioral sciences. Hillsdale, NJ: Lawrence Erlbaum.

Coie, J. D., Dodge, K. A., Terry, R., \& Wright, V. (1991). The role of aggression in peer relations: An analysis of aggression episodes in boys' play groups. Child Development, 62, 812-826.

Craig, W. M. (1998). The relationship among bullying, victimization, depression, anxiety and aggression in elementary school children. Personality and Individual Differences, 24, 123-130.

Crick, N. R. (1996). The role of overt aggression, relational aggression, and prosocial behaviour in the prediction of children's future social adjustment. Child Development, 67, 2317-2327.

Crick, N. R. (1997). Engagement in gender normative versus nonnormative forms of aggression: Links to social-psychological adjustment. Developmental Psychology, 33, 610-617.

Crick, N. R., \& Bigbee, M. A. (1998). Relational and overt forms of peer victimization: A multiinformant approach. Journal of Consulting and Clinical Psychology, 66, 337-347.

Crick, N. R., Casas, J. F., \& Hyon-Chin, K. (1999). Relational and physical forms of peer victimization in preschool. Developmental Psychology, 35, 376-385.

Crick, N. R., Casas, J. F., \& Mosher, M. (1997). Relational and overt aggression in preschool. Developmental Psychology, 33, 579-588.

Crick, N. R., \& Grotpeter, J. K. (1995). Relational aggression, gender, and social-psychological adjustment. Child Development, 66, 710-722.

Crick, N. R., \& Grotpeter, J. K. (1996). Children's treatment by peers: Victims of relational and overt aggression. Development and Psychopathology, 8, 367-380.

Dodge, K. A. (1986). A social information processing model of social competence in children. In M. Perlmutter (Ed.), The Minnesota Symposium on Child Psychology, Vol. 18 (pp. 77-125). Hillsdale, NJ: Lawrence Erlbaum.

Egan, S. K., \& Perry, D. G. (1998). Does low self-regard invite victimization? Developmental Psychology, 34, 299-309.

Elander, J., \& Rutter, M. (1996). An update on the status of the Rutter parents' and teachers' scales. Child Psychology and Psychiatry Review, 1, 31-35.

Eysenck, H. J., \& Eysenck, S. B. G. (1975). Manual of the Eysenck Personality Questionnaire. London: Hodder \& Stoughton. 
Farrington, D. P. (1993). Understanding and preventing bullying. In M. Tonry (Ed.), Crime and justice, Vol. 17 (pp. 381-458). Chicago: University of Chicago.

Farrington, D. P. (1995). The Twelfth Jack Tizard Memorial Lecture: The development of offending and antisocial behaviour from childhood: Key findings from the Cambridge Study in delinquent development. Journal of Child Psychology and Psychiatry, 36, 929-964.

Feldman, E., \& Dodge, K. A. (1987). Social information processing and sociometric status: Sex, age, and situational effects. Journal of Abnormal Child Psychology, 15, 211-227.

Fergusson, D. M., Horwood, L. J., \& Lawton, J. M. (1990). Vulnerability to childhood problems and family social background. Journal of Child Psychology and Psychiatry, 31, 1145-1160.

Fonagy, P., \& Target, M. (1997). Attachment and reflective function: Their role in self-organization. Development and Psychopathology, 9, 679-700.

Gasteiger-Klicpera, B., \& Klicpera, C. (1997). Aggressivität und soziale Stellung in der Klassengemeinschaft. Zeitschrift für Kinder und Jugenpsychiatrie, 25, 139-150.

Genta, M. L., Menesini, E., Fonzi, A., Costabile, A., \& Smith, P. K. (1996). Bullies and victims in schools in central and southern Italy. European Journal of Psychology of Education, $11,97-110$.

Gilmartin, B. G. (1987). Peer group antecedents of severe loveshyness in males. Journal of Personality, 55, 467-489.

Goodman, R. (1997). The Strengths and Difficulties Questionnaire: A research note. Journal of Child Psychology and Psychiatry, 38, 581-586.

Goodman, R., \& Scott, S. (1999). Comparing the Strengths and Difficulties Questionnaire and the Child Behavior Checklist: Is small beautiful? Journal of Abnormal Child Psychology, 27, $17-24$.

Hanewinkel, R., \& Knaack, R. (1997). Mobbing: Eine Fragebogenstudie zum Ausmass von Aggression und Gewalt an Schulen. Empirische Pädagogik, 11, 403-422.

Harachi, T. W., Catalano, R. F., \& Hawkins, J. D. (1999). Canada. In P. K. Smith, Y. Morita, J. Junger-Tas, D. Olweus, R. Catalano, \& P. Slee (Eds.), The nature of school bullying: A cross-national perspective (pp. 296-306). London: Routledge.

Harter, S. (1985). The Self-Perception Profile for Children: Revision of the Perceived Competence Scale for Children. Manual. Denver, CO: University of Denver.

Hirano, K. (1992). Bullying and victimisation in Japanese classrooms. Paper presented at the European Conference on Developmental Psychology, Spain.

KIDSCAPE. (1998) World first study into long-term effects of bullying as presented at Kidscape conference: "Bullying: Successful ways to stop it", London, 21 April 1998.

Klasen, H., Woerner, W., Wolke, D., Meyer, R., Overmeyer, S., Kaschnitz, W., Rothenberger, A., \& Goodman, R. (in press). Comparing the German versions of the Strengths and Difficulties (SDQ-Deu) and the Child Behavior Checklist. European Journal of Child and Adolescent Psychiatry.

Kochenderfer, B. J., \& Ladd, G. W. (1997). Victimized children's responses to peers' aggression: Behaviours associated with reduced versus continued victimization. Development and Psychopathology, 9, 59-73.

Kumpulainen, K., Räsänen, E., Henttonen, I., Almqvist, F. Kresanov, K., Linna, S. -L., Moilanen, I., Piha, J., Puura, K., \& Tamminen, T. (1998). Bullying and psychiatric symptoms among elementary school-age children. Child Abuse and Neglect, 22, 705-717.

Lagerspetz, K. M. J., \& Björkqvist, K. (1994). Indirect aggression in boys and girls. In L. R. Huesmann (Ed.), Aggressive behaviour: Current perspectives (pp. 131-149). New York: Plenum Press.

Lagerspetz, K. M. J., Björkqvist, K., \& Peltonen, T. (1988). Is indirect aggression typical of females? Aggressive Behaviour, 14, 403-414.
Lahey, B. B., Waldman, L. D., \& McBurnett, K. (1999). The development of antisocial behavior: An integrative causal model. Journal of Child Psychology and Psychiatry, 40, 669-682.

Loeber, R., \& Hay, D. F. (1994). Developmental approaches to aggression and conduct problems. In M. Rutter \& D. F. Hay (Eds.), Development through life: A handbook for clinicians (pp. 488-516). Oxford: Blackwell Scientific Publications.

Lowenstein, L. F. (1977). Who is the bully. Home and School, 11, 3-4.

Matsui, T., Kakuyama, T., Tsuzuki, Y., \& Onglatco, M.-L. (1996). Long-term outcomes of early victimization by peers among Japanese male university students: Model of a vicious cycle. Psychological Reports, 79, 711-720.

McClure, M., \& Sirataki, S. (1989). Child psychiatry in Japan. Journal of the American Academy of Child and Adolescent Psychiatry, 28, 488-492.

Menesini, E., Eslea, M., Smith, P. K., Genta, M. L., Giannetti, E., Fonzi, A., \& Costabile, A. (1997). Cross-national comparison of children's attitudes towards bully/victim problems in school. Aggressive Behaviour, 23, 245-257.

Moffitt, T. E., Caspi, A., Harkness, A. R., \& Silva, P. A. (1993). The natural history of change in intellectual performance: Who changes? How much? Is it meaningful? Journal of Child Psychology and Psychiatry, 33, 441-453.

Mooij, T. (1992). Pesten in het onderwijs. Nijmegen, The Netherlands: Instituut voor Toegepaste Sociale Wetenschappen.

Morita, Y., Soeda, H., Soeda, K., \& Taki, M. (1999). Japan. In P. K. Smith, Y. Morita, J. Junger-Tas, D. Olweus, R. Catalano, \& P. Slee (Eds.), The nature of school bullying: A cross-national perspective. London: Routledge.

Mynard, H., \& Joseph, S. (1997). Bully/victim problems and their association with Eysenck's personality dimensions in 8 to 13 years olds. British Journal of Educational Psychology, 67, 51-54.

Myron-Wilson, R. (1999). Parental style and how it may influence a child's role in bullying. Paper presented at the Research in Child Development Conference, Alberqueque, New Mexico.

Myron-Wilson, R., \& Smith, P. K. (1997). Attachment relationships and influences on bullying. Paper presented at the British Psychological Society Developmental Section Conference, England.

Neary, A., \& Joseph, S. (1994). Peer victimization and its relationship to self-concept and depression among schoolgirls. Personality and Individual Differences, 16, 183-186.

Olweus, D. (1978). Aggression in the schools: Bullies and whipping boys. New York: John Wiley \& Sons.

Olweus, D. (1993). Bullying in schools: What we know and what we can do. Oxford: Blackwell Publishers.

Olweus, D. (1994). Annotation: Bullying at school: Basic facts and effects of a school-based intervention program. Journal of Child Psychology and Psychiatry, 35, 1171-1190.

Olweus, D. (1999). Norway. In P. K. Smith, Y. Morita, J. Junger-Tas, D. Olweus, R. Catalano, \& P. Slee (Eds.), The nature of school bullying: A cross-national perspective (pp. 28-48). London: Routledge.

O'Moore, A. M., \& Hillery, B. (1989). Bullying in Dublin schools. The Irish Journal of Psychology, 10, 426-441.

O'Moore, A. M., Kirkham, C., \& Smith, M. (1997). Bullying behaviour in Irish schools: A nationwide study. The Irish Journal of Psychology, 18, 141-169.

Pereira, B., Mendonca, D., Neto, C., Almeida, A., Valente, L., $\&$ Smith, P. K. (1996). Facts and figures of the first survey on bullying in Portugese schools. Paper presented at the European Conference on Educational Research, Seville.

Perry, D. G., Kusel, S. J., \& Perry, L. C. (1988). Victims of peer aggression. Developmental Psychology, 24, 807-814.

Pulkkinen, L., \& Tremblay, R. E. (1992). Patterns of boys' social adjustment in two cultures and at different ages: A 
longitudinal perspective. International Journal of Behavioural Development, 15, 527-553.

Rigby, K. (1993). School children's perceptions of their families and parents as a function of peer relations. The Journal of Genetic Psychology, 154, 501-513.

Rigby, K. (1994). Psychosocial functioning in families of Australian adolescent school children involved in bully/ victim problems. Journal of Family Therapy, 16, 173-187.

Rigby, K. (1998). Peer relations at school and the health of adolescents. Youth Studies Australia, 17, 13-17.

Rigby, K. (1999). Peer victimisation at school and the health of secondary school students. British Journal of Educational Psychology, 69, 95-104.

Rivers, I., \& Smith, P. K. (1994). Types of bullying behaviour and their correlates. Aggressive Behaviour, 20, 359-368.

Roecker, C. E., Caprini, J., Dickerson, J., Parks, E., \& Barton, A. (1999). Children's responses to overt and relational aggression. Paper presented at the the Biennial Meeting of the Society for Research in Child Development, Albuquerque, New Mexico.

Rotenberg, K. J. (1986). Causes, intensity, motives and consequences of children's anger from self-reports. Journal of Genetic Psychology, 146, 101-106.

Rutter, M. (1967). A children's behavior questionnaire for completion by teachers: Preliminary findings. Journal of Child Psychology and Psychiatry, 8, 1-11.

Rutter, M., Tizard, J., \& Whitmore, K. (1970). Education, health and behavior. London: Longman.

Salmon, G., James, A., \& Smith, D. M. (1998). Bullying in schools: Self-reported anxiety, depression, and self-esteem in secondary school children. British Medical Journal, 317, 924-925.

Schäfer, M., Werner, N. E., \& Crick, N. R. (2000). Relational victimization, physical victimization, and bullying among German school children: Relations among constructs, gender differences, and links with adjustment. Manuscript submitted for publication.

Schwartz, D., Dodge, K. A., Pettit, G. S., \& Bates, J. E. (1997). The early socialization of aggressive victims of bullying. Child Development, 68, 665-675.

Schwartz, D., McFadyen-Ketchum, S. A., Dodge, K. A., Pettit, G. S., \& Bates, J. E. (1998). Peer group victimization as a predictor of children's behaviour problems at home and in school. Development and Psychopathology, 10, 87-99.

Sharp, S. (1995). How much does bullying hurt? The effects of bullying on the personal wellbeing and educational progress of secondary aged students. Educational and Child Psychology, 12, 81-88.

Skuse, D. H. (1997). Genetic factors in the etiology of child psychiatric disorders. Current Opinion in Pediatrics, 9, 354-360.
Slee, P. T. (1994). Situational and interpersonal correlates of anxiety associated with peer victimization. Child Psychiatry and Human Development, 25, 97-107.

Slee, P. T. (1995). Peer victimization and its relationship to depression among Australian primary school students. Personality and Individual Differences, 18, 57-62.

Slee, P. T., \& Rigby, K. (1993). The relationship of Eysenck's personality factors and self-esteem to bully-victim behaviour in Australian schoolboys. Personality and Individual Differences, 14, 371-373.

Smith, P. K. (1991). The silent nightmare: Bullying and victimisation in school peer groups. The Psychologist: Bulletin of the British Psychological Society, 4, 243-248.

Smith, P. K., \& Levan, S. (1995). Perceptions and experiences of bullying in younger pupils. British Journal of Educational Psychology, 65, 489-500.

Smith, P. K., Morita, Y., Junger-Tas, J., Olweus, D., Catalano, R., \& Slee, P. (1999). The nature of school bullying: A crossnational perspective. London: Routledge.

Sutton, J., \& Smith, P. K. (1999). Bullying as a group process: An adaptation of the participant role approach. Aggressive Behaviour, 25, 97-111.

Sutton, J., Smith, P. K., \& Swettenham, J. (1999). Bullying and "theory of mind": A critique of the "social skills deficit" view of anti-social behaviour. Social Development, 8, $117-127$.

Vettenburg, N. (1999). Belgium. In P. K. Smith, Y. Morita, J. Junger-Tas, D. Olweus, R. Catalano, \& P. Slee (Eds.), The nature of school bullying: A cross-national perspective. London: Routledge.

Wariyar, U. K., \& Richmond, S. (1989). Morbidity and preterm delivery: Importance of $100 \%$ follow-up. The Lancet, 18 , 387-388.

Whitney, I., \& Smith, P. K. (1993). A survey of the nature and extent of bullying in junior/middle and secondary schools. Educational Research, 35, 3-25.

Wolke, D., \& Karstadt, L. (1999). End of award report: Physical and relational bullying in young children: Distinguishing features (R000222563). Economic and Social Research Council, Great Britain.

Wolke, D., Söhne, B., Ohrt, B., \& Riegel, K. (1995). Follow-up of preterm children: Important to document dropouts. The Lancet, 345, 447.

Wolke, D., \& Stanford, K. (1999). Bullying in school children. In D. Messer \& S. Millar (Eds.), Developmental psychology. London: Arnold.

Wolke, D., Woods, S., Schulz, H., \& Stanford, K. (2000) Bullying and victimisation of primary school children in south England and south Germany: Prevalence and school factors. Manuscript submitted for publication.

Manuscript accepted 3 May 2000 